\title{
Genetic testing in families with hereditary colorectal cancer in British Columbia and Yukon: a retrospective cross-sectional analysis
}

\author{
Vivienne K. Beard BSc, Angela C. Bedard MS, Jennifer Nuk MSc, Petra W.C. Lee BSc, Quan Hong MSc, \\ James E.J. Bedard PhD, Sophie Sun MD, Kasmintan A. Schrader MBBS PhD
}

\section{Abstract}

Background: Genetic testing in families with hereditary cancer enables identification of people most likely to benefit from intensive screening and preventive measures; however, the uptake of testing in relatives (known as cascade carrier testing) for hereditary colorectal cancer syndromes has been shown to be low. Our objective was to report rates of familial testing for hereditary colorectal cancer syndromes in a publicly funded hereditary cancer clinic in Canada.

Methods: A cross-sectional retrospective database review was used to determine testing uptake between 1997 and 2016 for families served by the provincial Hereditary Cancer Program for British Columbia and Yukon. Analyses were conducted for genes associated with syndromes with an increased risk for colorectal cancer, including Lynch syndrome (MLH1, MSH2, MSH6, PMS2 and EPCAM) and familial adenomatous polyposis (APC), and for additional moderate- to high-penetrance genes (STK11, TP53, SMAD4, MUTYH, PTEN and CHEK2). Descriptive statistics were used and all analyses were 2-tailed.

Results: The study cohort included 245 index patients, with carrier testing performed in 382 relatives. The mean age at family member testing was 41.2 years, and most $(61.0 \%)$ of the family members who underwent testing were women. The median time between disclosure of index cases and their family member's results was 8.3 months. Among eligible first-degree relatives, 32.6\% (268/821) underwent testing in BC. Of 67 cancer diagnoses in family members, most $(62.7 \%)$ occurred before genetic testing.

Interpretation: A substantial proportion of people at risk for hereditary colorectal cancer do not undergo genetic testing. This gap highlights the need to explore barriers to testing and to consider interventions to promote uptake; more aggressive efforts by hereditary cancer programs are needed to reach this highest risk population.

\begin{abstract}
t is estimated that $5 \%-6 \%$ of colorectal cancers are due to a hereditary cancer syndrome. ${ }^{1,2}$ Genetic testing in at-risk relatives, known as cascade carrier testing, identifies those most likely to benefit from increased screening and preventive measures, leading to earlier detection and decreased cancer incidence. ${ }^{3}$ The cost-effectiveness of broad panel genetic testing relies on uptake of targeted carrier testing and arguably on the effectiveness of hereditary cancer programs in general. ${ }^{4-6}$

The most common hereditary colorectal cancer syndrome, Lynch syndrome, accounts for up to $5 \%$ of colorectal cancers. ${ }^{2}$ People with Lynch syndrome have up to an $80 \%$ and $60 \%$ lifetime risk (up to age $80 \mathrm{yr}$ ) for colorectal and endometrial cancer, respectively. ${ }^{7}$ In people with more rare hereditary colorectal cancer syndromes such as familial adenomatous polyposis and $M U T Y H$-associated polyposis, there is up to a $100 \%$ colorectal cancer lifetime risk (to age $80 \mathrm{yr}$ ) without appropriate surveillance. ${ }^{8}$ Given the substantially higher cancer risk among
\end{abstract}

people with these syndromes than in the general population, identifying those at risk is an important health care priority. ${ }^{9}$

Reports suggest variable carrier testing rates in clinic-based and cancer registry-based studies of at-risk relatives, ranging from $34 \%$ to $75 \% .^{4,10-23}$ Most people who have received carrier testing for Lynch syndrome are satisfied in the long term with receiving testing, ${ }^{11}$ as carrier testing enables them to make more informed decisions and to receive personalized health care. ${ }^{24}$ Noncarriers also benefit from carrier testing, as

\section{Competing interests: None declared.}

This article has been peer reviewed.

Correspondence to: Kasmintan Schrader, ischrader@bccancer.bc.ca; Angela Bedard, angela.bedard @ bccancer.bc.ca

CMAJ Open 2020. DOI:10.9778/cmajo.20190167 
negative test results may reduce cancer-related anxiety ${ }^{25}$ and can eliminate the need for intensive screening. ${ }^{16}$ Many studies have found that substantially higher numbers of women than men receive carrier testing. ${ }^{12,16,21}$ Some studies have also related age to carrier testing uptake, with lower rates of testing in first-degree relatives younger than 25 years of age for Lynch syndrome ${ }^{21}$ and older than 40 years of age for familial adenomatous polyposis. ${ }^{16}$

To understand the uptake of carrier testing in a Canadian context, our objective was to report rates of familial testing for hereditary cancer syndromes associated with an increased risk for colorectal cancer in a publicly funded hereditary cancer clinic over a 20-year period.

\section{Methods}

\section{Setting and study population}

This study was a retrospective cross-sectional database review using population-based data from the Hereditary Cancer Program (HCP) for British Columbia and Yukon. This program is the sole provider of publicly funded cancer genetic testing in these jurisdictions. Demographic data and personal medical and family history information for patients assessed between Jan. 1, 1997, and Dec. 31, 2016, were obtained using the HCP clinical and BC Cancer electronic chart databases.

Individuals found to carry a pathogenic or likely pathogenic variant (i.e., the index patient) tested through the HCP program were included in the study. Their family members known or presumed to be living in BC or Yukon were included in the cascade carrier analysis. Family members confirmed to be living outside of British Columbia or Yukon were excluded from the analysis, although it should be noted that geographic location of unaffected family members is not routinely assessed or recorded in the HCP database.

The index patients and their family members were identified through the HCP clinical database; this database is maintained using the software Progeny, a genetic pedigree and medical record program commonly used in medical genetics. Previous research experience with these data sets has indicated high levels of consistency between clinical and genetic diagnoses in Progeny and the BC Cancer database (Matthew Richardson, Hereditary Cancer Program, BC Cancer, Vancouver, BC: personal communication, 2020).

The genetic variants assessed were all linked to a risk for hereditary colorectal cancer. The autosomal dominant conditions Lynch syndrome (MLH1, MSH2, MSH6, PMS2 and $E P C A M)$, familial adenomatous polyposis $(A P C)$, Li-Fraumeni syndrome (TP53), Peutz-Jeghers syndrome (STK11), juvenile polyposis (SMAD4) and PTEN hamartoma tumour syndrome (which includes Cowden syndrome; PTEN), and CHEK2 where first-degree relatives of gene-positive individuals have a $50 \%$ risk of carrying the familial pathogenic variant, were included. ${ }^{16}$

Additionally, we included the autosomal recessive syndrome $M U T Y H$-associated polyposis, where at-risk relatives may have a $25 \%$ risk of homozygous or biallelic MUTYH pathogenic variant status. ${ }^{16}$ For this syndrome, families identified through index cases with biallelic MUTYH pathogenic or likely pathogenic variants were included in the analysis, with only siblings deemed as eligible individuals for testing.

For adult-onset syndromes (Lynch, Peutz-Jeghers, juvenile polyposis, PTEN hamartoma tumour syndrome [which includes Cowden syndrome] and CHEK2), relatives were considered eligible for carrier testing if they were 19 years of age or older and living in BC or Yukon. In the case of childhoodonset syndromes (Li-Fraumeni, familial adenomatous polyposis), living relatives of all ages were eligible.

\section{Cascade carrier testing}

In-depth pedigree analyses were performed for each index patient to ascertain the number of eligible first-degree relatives and the number of relatives tested by degree (first through fourth degree). The pedigrees and test results were recorded as part of routine medical care in the HCP database, while the determination of eligible relatives versus actual relatives tested was performed for the study (V.B.). Relatives' eligibility for testing was determined by existing HCP clinical criteria. In the case of multiple tests performed in 1 family, the first individual tested was considered the index patient. The median time between the index and carrier tests per gene was determined by calculating the difference between the date of disclosure of index and all carrier test results.

\section{Cohort characteristics}

Summary statistics were calculated to describe the population of index patients and relatives receiving carrier tests by age, sex, rural or urban residence and referral method. The location of the patient's residence (urban v. rural) was determined from their 6-digit postal code. The types and number of cancers diagnosed in patients before and after carrier testing were extracted from the BC Cancer database and assessed to determine the health impact of carrier testing. We included all cancer types in this analysis, including nonmelanomatous skin cancers and cervical cancer.

\section{Statistical analysis}

Descriptive statistics were calculated using Microsoft Excel 2016. Results were reported as means and standard deviations or medians and ranges for continuous variables and as proportions or frequencies for categorical variables. $\mathrm{R}$ version 3.3.4 was used to perform $\chi^{2}$ tests to determine uptake by sex and age as well as to perform univariate and multivariate analyses to assess the relationship of age, sex, urban or rural residence and cancer diagnosis with testing uptake. Univariate and multivariate analyses were employed to assess factors related to the time interval between index and carrier tests. All statistical analyses were 2-tailed with a statistical significance of $p$ less than or equal to 0.05 .

\section{Ethics approval}

This study was reviewed and approved by the University of British Columbia - BC Cancer Research Ethics Board and the Human Research Ethics Board of the University of the Fraser Valley. 


\section{Results}

The study cohort included 245 index patients tested between Jan. 1, 1997, and Dec. 31, 2016. During this period, carrier testing was performed for 382 relatives of the index patients (first through fourth degree). Demographic data and source of referral for the index patients and relatives receiving carrier testing are reported in Table 1.

For the index patients, the cohort included 150 (61.2\%) women and 95 (38.8\%) men. Pathogenic or likely pathogenic variants were identified in Lynch syndrome genes for 157 $(64.1 \%)$ of the index patients. The mean age at index testing was 49.3 (standard deviation [SD] 15.1) years, and 209 $(85.3 \%)$ and $24(9.8 \%)$ patients lived in urban and rural areas, respectively (Table 1).

Among the 382 family members who underwent carrier testing, 233 (61.0\%) were women and 149 (39.0\%) were men. The mean age at carrier testing was 41.2 (SD 17.7) years. Among those who underwent carrier testing, 332 (86.9\%) lived in urban regions; 35 (9.2\%) lived in rural regions.

The most common source of referral was a medical specialist for the index patients (129 patients, 52.7\%) and selfreferral for those undergoing carrier testing (185 family members, $48.4 \%$ ). Self-referral was the only characteristic of index

Table 1: Demographic characteristics of people who received index or carrier testing in British Columbia or Yukon through the BC Hereditary Cancer Program, 1997-2006

\begin{tabular}{|c|c|c|}
\hline \multirow[b]{2}{*}{ Characteristic } & \multicolumn{2}{|c|}{ No. $(\%)$ of people* } \\
\hline & $\begin{array}{c}\text { Index patients } \\
n=245\end{array}$ & $\begin{array}{c}\text { Relatives } \\
\text { receiving } \\
\text { carrier } \\
\text { testing } \\
n=382\end{array}$ \\
\hline \multicolumn{3}{|l|}{ Sex } \\
\hline Female & $150(61.2)$ & $233(61.0)$ \\
\hline Male & $95(38.8)$ & 149 (39.0) \\
\hline Age, yr; mean \pm SD & $49.3 \pm 15.1$ & $41.2 \pm 17.7$ \\
\hline \multicolumn{3}{|l|}{ Residence } \\
\hline Urban & $209(85.3)$ & 332 (86.9) \\
\hline Rural & $24(9.8)$ & $35(9.2)$ \\
\hline Unspecified & $12(4.9)$ & $15(3.9)$ \\
\hline \multicolumn{3}{|l|}{ Referral source } \\
\hline Self & $16(6.5)$ & $185(48.4)$ \\
\hline Family doctor & $46(18.8)$ & $77(20.2)$ \\
\hline Specialist doctor & $129(52.7)$ & $37(9.7)$ \\
\hline Family member & $8(3.3)$ & $33(8.6)$ \\
\hline Hereditary cancer program & $1(0.4)$ & $5(1.3)$ \\
\hline Unspecified or other & $45(18.4)$ & $45(11.8)$ \\
\hline $\begin{array}{l}\text { Note: SD = standard deviation } \\
\text { *Unless indicated otherwise. } \\
\text { †First- to fourth-degree family membe }\end{array}$ & & \\
\hline
\end{tabular}

patients that was significantly correlated with increased carrier testing in first-degree relatives $(p=0.03)$.

\section{Cascade carrier testing}

Figure 1 shows the uptake of carrier testing in eligible firstdegree relatives of index patients in $\mathrm{BC}$ and Yukon. Of 821 first-degree relatives eligible for testing, 268 (32.6\%) received carrier testing. The highest uptake was half of all eligible first-degree relatives for CHEK2 (5/10; 50.0\%, 95\% confidence interval [CI] $19 \%$ to $81 \%$ ) and SMAD4 (3/6; $50.0 \%, 95 \%$ CI $10 \%$ to $90 \%$ ), and the lowest uptake was $10.7 \%$ of first-degree relatives of MUTYH-associated polyposis $(3 / 28,95 \% \mathrm{CI}-1 \%$ to $22 \%)$. We identified 91 families with eligible first-degree relatives in BC and Yukon with no carrier tests performed.

The total cascade carrier rate across all genes among all relatives receiving carrier testing was 1.56 carrier tests per index patient (382/245) (Table 2). The median time to carrier testing was 8.3 (range $0-170.3$ ) months. The median time to testing for the 5 Lynch syndrome genes was 8.2 (range $0-143.0)$ months. The age of the family member was significantly correlated with the time to uptake of carrier testing, with younger family members having a longer time gap before pursuing testing $(p<0.001)$. Among relatives who were women and those who referred themselves to the program, a trend toward shorter time to uptake for testing was observed; however, these findings were not statistically significant.

\section{Cancer diagnoses}

A total of 67 cancer diagnoses were identified in carriers of a colorectal cancer-related gene. Colorectal cancer was the most commonly diagnosed type of cancer $(n=32 ; 47.8 \%)$, followed by breast cancer $(n=8 ; 11.9 \%)$ and endometrial cancer $(n=7 ; 10.4 \%)$. Most cancer diagnoses $(n=42 ; 62.7 \%)$ occurred before carrier testing; 25 of the diagnoses (37.3\%) occurred after testing.

\section{Interpretation}

In this retrospective analysis, we assessed the uptake of genetic testing in 245 families with a known familial pathogenic or likely pathogenic variant in a colorectal cancer-related gene. The index patients from these families were ascertained from our general clinic population, which has an approximately $11 \%$ mutation detection rate across these genes (Matthew Richardson, Hereditary Cancer Program, BC Cancer, Vancouver, BC: unpublished data, 2020). Across the 12 genes analyzed, the uptake of testing was 1 in 3 eligible first-degree relatives. The most common genes tested for were those related to the relatively common Lynch syndrome, which comprised $64.1 \%$ of index diagnoses; overall uptake was highest in female relatives. The uptake of testing for Lynch syndrome in first-degree relatives in previous reports has ranged between $34 \%$ and $94 \% .{ }^{14-16,20-22}$

To date, reports on cascade carrier rates have differed widely across studies. We identified a rate of 1.56 carrier tests per index case across all 12 genes. Similar rates of 


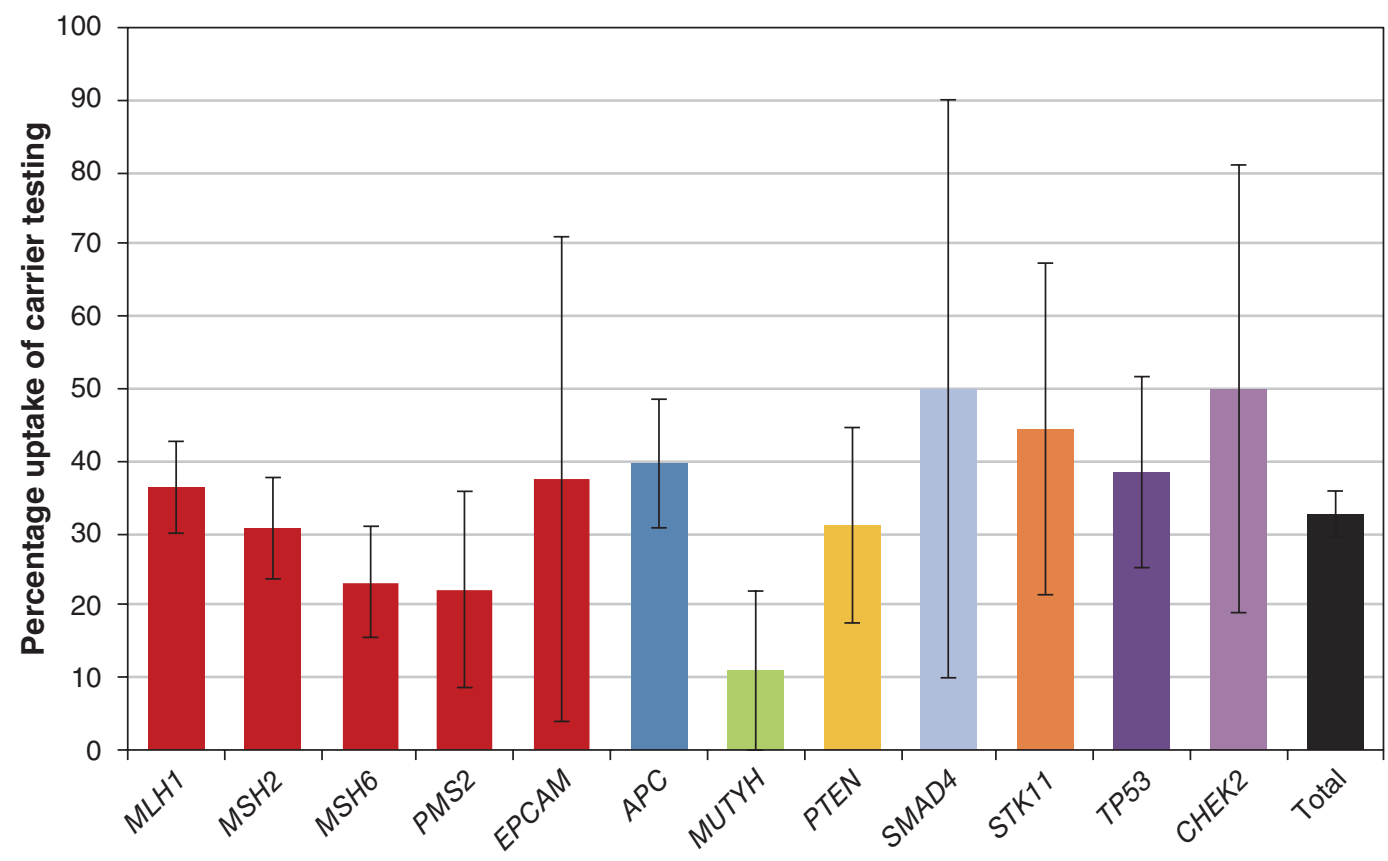

Figure 1: Percentage of eligible first-degree relatives who have received carrier testing. See Appendix 1 (available at www.cmajopen.ca/ content/8/4/E637/suppl/DC1) for raw data. Of 821 eligible first-degree relatives, 268 received carrier testing. Error bars represent $95 \%$ confidence intervals.

$1.5^{14}$ and $1.04^{13}$ relatives tested per index patient have previously been reported for Lynch syndrome. However, other studies have reported rates of $4.6^{26}$ and $3.6^{16}$ carrier tests per index patient, demonstrating large variability in cascade carrier testing between populations. This variability highlights the value of a population-based approach to assessing carrier testing, as uptake rates may differ greatly between clinics and countries.

The proportion of patients from rural areas in this study was lower than we might have expected on the basis of census data. During the study period (1997-2016), 9.2\% of family members completing carrier testing for hereditary colorectal cancer were from rural regions in $\mathrm{BC}$; this percentage is lower than the overall percentage of $\mathrm{BC}$ residents who lived in rural areas in $1996(18 \%)^{27}$ and $2016(14 \%) .{ }^{28}$ Some studies have shown disparities in awareness among rural populations, ${ }^{29}$ whereas others have demonstrated higher uptake of testing when alternative methods like telephone counselling are used. ${ }^{30}$ These findings support the development and use of alternative modes for education service delivery to rural populations to ensure equitable access. They also highlight the importance of patient self-referrals. Many programs across Canada require a physician referral for hereditary cancer services. Canadians living in rural areas have decreased access to family physicians ${ }^{31}$ and thus face even greater barriers to receiving specialty care if physician referral is required. Our study showed greater numbers of tests in families that started with our program through self-referral and a trend toward a shorter wait time when they initiated their own referral (although this latter finding was not statistically significant).

A previous cancer diagnosis has been identified as a predictor of carrier testing. ${ }^{32}$ We found that nearly two-thirds $(62.7 \%)$ of cancer diagnoses in carriers were diagnosed before carrier testing, similar to the percentage found in another Canadian study on Lynch syndrome (63.4\%). ${ }^{33}$ Considering that a major goal of carrier testing is cancer prevention through intensive screening and prophylactic measures, it is important to reach at-risk relatives before they are diagnosed with cancer. ${ }^{34}$ Further investigation into the health impact of carrier testing for colorectal cancerrelated syndromes is necessary.

Fears about life insurance and mortgage implications are commonly reported reasons for declining carrier testing. ${ }^{18} \mathrm{In}$ 2017, Canada enacted the Genetic Non-Discrimination Act, preventing insurance companies, employers and people involved in any contract from requiring individuals to disclose genetic test results. ${ }^{35}$ The law was upheld in 2020 by the Supreme Court of Canada after a challenge related to jurisdictional concerns. ${ }^{36}$ Research investigating carrier testing rates before and after enactment will be an important subject of future research.

Recent systematic reviews on cascade carrier screening point to the limitation of the index patient being responsible 


\begin{tabular}{|c|c|c|c|c|}
\hline \multirow[b]{2}{*}{ Gene } & \multirow{2}{*}{$\begin{array}{l}\text { No. of } \\
\text { recipients of } \\
\text { carrier testing }\end{array}$} & \multicolumn{2}{|c|}{$\begin{array}{c}\text { Characteristics of recipients of carrier } \\
\text { testing }\end{array}$} & \multirow{2}{*}{$\begin{array}{c}\text { Time difference between index } \\
\text { and carrier testing, mo, } \\
\text { median (range) }\end{array}$} \\
\hline & & Female, no. (\%) & $\begin{array}{c}\text { Age, yr, } \\
\text { mean } \pm S D\end{array}$ & \\
\hline PTEN & 16 & $11(68.8)$ & $31.1 \pm 19.6$ & $8.0(4.6-27.2)$ \\
\hline \multicolumn{5}{|l|}{ Lynch syndrome genes } \\
\hline MLH1 & 110 & $64(58.2)$ & $41.1 \pm 15.7$ & $7.8(0-91.3)$ \\
\hline MSH2 & 103 & $63(61.2)$ & $43.9 \pm 14.7$ & $11.9(0-143)$ \\
\hline MSH6 & 36 & $21(58.3)$ & $46.8 \pm 19.1$ & $6.0(1.1-43.5)$ \\
\hline PMS2 & 6 & $4(66.7)$ & $56.0 \pm 8.8$ & $11.6(2.9-13.4)$ \\
\hline EPCAM & 3 & 0 & $43.0 \pm 23.0$ & $3.2(3.2-29.8)$ \\
\hline Total & 258 & $152(58.9)$ & $43.4 \pm 15.9$ & $8.2(0-143.0)$ \\
\hline MUTYH (biallelic index) & 6 & 5 (83.3) & $53.0 \pm 11.0$ & $6.1(4.8-21.3)$ \\
\hline$A P C$ & 58 & $38(65.5)$ & $33.6 \pm 20.3$ & $12.9(1.4-170.3)$ \\
\hline STK11 & 7 & $4(57.1)$ & $48.0 \pm 24.0$ & $8.4(0-36.4)$ \\
\hline SMAD4 & 5 & $1(20.0)$ & $32.0 \pm 28.0$ & $24.2(6.0-28.7)$ \\
\hline CHEK2 & 4 & $4(100.0)$ & $46.0 \pm 17.0$ & $3.7(2.7-25.1)$ \\
\hline TP53 & 28 & $18(64.3)$ & $35.6 \pm 17.8$ & $7.6(1.1-84.7)$ \\
\hline Overall total & 382 & $233(61.0)$ & $41.2 \pm 17.7$ & $8.3(0-170.3)$ \\
\hline
\end{tabular}

to inform all at-risk relatives. ${ }^{9,23}$ Although this remains the standard procedure in most hereditary cancer programs, including that of BC Cancer, studies where health professionals also contacted relatives have reported higher rates of testing uptake. ${ }^{15,16,20-22}$ Policy and legal considerations are needed when proposing direct contact with relatives, making this an area for further research.

Our results highlight the need to explore barriers and develop tailored interventions to promote testing uptake. Further research is also needed to examine the effect of demographic factors such as socioeconomic status and ethnicity on uptake of testing, as there is evidence of disparities in cancer screening among Canadians of minority and lower socioeconomic backgrounds. ${ }^{38}$ This will help guide decision-making regarding education and resource allocation to optimize carrier testing uptake.

\section{Limitations}

An important limitation of this study is that we included only index tests and associated carrier tests conducted in BC and Yukon in the analyses to ensure accuracy of data. However, many carrier tests have been performed through the HCP for family members for whom the initial family member who tested positive resided outside of $\mathrm{BC}$ or Yukon, and these families were not included in our study. We are likely to have overestimated the number of family members living in BC or Yukon. The geographic location of unaffected relatives is not routinely assessed or recorded in the HCP health record.
Therefore, it is possible that some at-risk relatives received out-of-province carrier testing for which we did not have records. The cascade carrier testing rate may be higher than determined, because we were not able to precisely determine the percentage of first-degree relatives living in BC or Yukon.

Additionally, cancer diagnoses included only those for carriers living in $\mathrm{BC}$ or Yukon because of limited access to data for cancer diagnoses for family members living elsewhere. The diagnoses we included in the study included all types of cancer (e.g., nonmelanomatous skin cancers and cervical cancer), not just those specific to the colorectal syndromes.

Although our data captured index and carrier tests performed over 20 years, people tested between 2017 and the time of data collection were not included in the analyses. Future analyses that assess carrier testing after 2016 will serve as valuable contributions to the growing body of carrier testing literature.

Although this study was performed in a single program in 1 province and territory, our estimation of cascade testing rates is probably still helpful. British Columba is the largest province in Canada with a single hereditary cancer program serving all residents; such an analysis in other large provinces may be difficult given the fragmentation of hereditary cancer care across several regional programs.

\section{Conclusion}

In this study, we found that a substantial proportion of people at risk for hereditary colorectal cancer in BC and Yukon have 
not received carrier testing. Studies that explore barriers to testing in this population may elucidate avenues for interventions to promote testing, with the ultimate goals of early detection and prevention of hereditary cancer.

\section{References}

1. Brosens LAA, Offerhaus GJA, Giardiello FM. Hereditary colorectal cancer: genetics and screening. Surg Clin North Am 2015;95:1067-80.

2. Jeter JM, Kohlmann W, Gruber S. Genetics of colorectal cancer. Oncology 2006;20:269-76

3. Howe JR, Ringold J, Hughes J, et al. Direct genetic testing for SMAD4 mutations in patients at risk for juvenile polyposis. Surgery 1999;126: $162-70$.

4. Sharaf RN, Myer P, Stave C, et al. Uptake of genetic testing by relatives of Lynch syndrome probands: a systematic review. Clin Gastroenterol Hepatol 2013;11:1093-100.

5. Hampel H. Genetic counseling and cascade genetic testing in Lynch syndrome. Fam Cancer 2016;15:423-7.

6. Wang VW, Koh P, Chow W, et al. Predictive genetic testing of first-degree relatives of mutation carriers is a cost-effective strategy in preventing hereditary non-polyposis colorectal cancer in Singapore. Fam Cancer 2012;11:279-89.

7. Aarnio M, Sankila R, Pukkala E, et al. Cancer risk in mutation carriers of DNA-mismatch-repair genes. Int 7 Cancer 1999;81:214-8.

8. Kantor M, Sobrado J, Patel S, et al. Hereditary colorectal tumors: a literature review on MUTYH-associated polyposis. Gastroenterol Res Pract 2017;2017:8693182.

9. Roberts MC, Dotson WD, DeVore CS, et al. Delivery of cascade screening for hereditary conditions: a scoping review of the literature. Health Aff (Millwood) 2018;37:801-8.

10. Lerman C, Hughes C, Trock BJ, et al. Genetic testing in families with hereditary nonpolyposis colon cancer. FAMA 1999;281:1618-22.

11. Aktan-Collan K, Mecklin JP, Järvinen H, et al. Predictive genetic testing for hereditary non-polyposis colorectal cancer: uptake and long-term satisfaction. Int 7 Cancer 2000;89:44-50.

12. Wagner A, Tops C, Wijnen J, et al. Genetic testing in hereditary nonpolyposis colorectal cancer families with a MSH2, MLH1, or MSH6 mutation. 7 Med Genet 2002;39:833-7.

13. Hadley DW, Jenkins J, Dimond E, et al. Genetic counseling and testing in families with hereditary nonpolyposis colorectal cancer. Arch Intern Med 2003;163:573-82.

14. Ponz de Leon M, Benatti P, Di Gregorio C, et al. Genetic testing among highrisk individuals in families with hereditary nonpolyposis colorectal cancer. $\mathrm{Br} F$ Cancer 2004:90:882-7.

15. Aktan-Collan K, Haukkala A, Pylvänäinen K, et al. Direct contact in inviting high-risk members of hereditary colon cancer families to genetic counselling and DNA testing. 7 Med Genet 2007;44:732-8.

16. Ramsoekh D, van Leerdam ME, Tops CM, et al. The use of genetic testing in hereditary colorectal cancer syndromes: genetic testing in HNPCC, (A)FAP and MAP. Clin Genet 2007;72:562-7.

17. Stoffel EM, Ford B, Mercado RC, et al. Sharing genetic test results in Lynch syndrome: communication with close and distant relatives. Clin Gastroenterol Hepatol 2008;6:333-8.

18. Lammens CR, Aaronson NK, Wagner A, et al. Genetic testing in Li-Fraumeni syndrome: uptake and psychosocial consequences. 7 Clin Oncol 2010; 28:3008-14.

19. Aktan-Collan KI, Kääriäinen HA, Kolttola EM, et al. Sharing genetic risk with next generation: mutation-positive parents' communication with their offspring in Lynch syndrome. Fam Cancer 2011;10:43-50.

20. Bruwer Z, Futter M, Ramesar R. Communicating cancer risk within an African context: experiences, disclosure patterns and uptake rates following genetic testing for Lynch syndrome. Patient Educ Couns 2013;92:53-60.

21. Barrow P, Green K, Clancy T, et al. Improving the uptake of predictive testing and colorectal screening in Lynch syndrome: a regional primary care survey. Clin Genet 2015;87:517-24.

22. Seppälä TT, Pylvänäinen K, Mecklin J-P. Uptake of genetic testing by the children of Lynch syndrome variant carriers across three generations. Eur 7 Hum Genet 2017;25:1237-45.

23. Menko FH, Ter Stege JA, van der Kolk LE, et al. The uptake of presymptomatic genetic testing in hereditary breast-ovarian cancer and Lynch syn- drome: a systematic review of the literature and implications for clinical practice. Fam Cancer 2019;18:127-35.

24. Levine FR, Coxworth J, Stevenson D, et al. Parental attitudes, beliefs, and perceptions about genetic testing for FAP and colorectal cancer surveillance in minors. 7 Genet Couns 2010;19:269-79.

25. Claes E, Denayer L, Evers-Kiebooms G, et al. Predictive testing for hereditary non-polyposis colorectal cancer: motivation, illness representations and short-term psychological impact. Patient Educ Couns 2004;55:265-74.

26. Baglietto L, Lindor NM, Dowty JG, et al.; Dutch Lynch Syndrome Study Group. Risks of Lynch syndrome cancers for MSH6 mutation carriers. 7 Natl Cancer Inst 2010;102:193-201.

27. Urban and rural population counts, for provinces and territories, 1996 census. CANSIM database. Ottawa: Statistics Canada; 1996. Cat no 93-357-XPB.

28. Table 32-10-0012-01-number of persons in the total population and the farm population, for rural areas and population centres classified by sex and age. CANSIM database. Ottawa: Statistics Canada; 2018.

29. Salloum RG, George TJ, Silver N, et al. Rural-urban and racial-ethnic differences in awareness of direct-to-consumer genetic testing. BMC Public Health 2018;18:277.

30. Kinney AY, Butler KM, Schwartz MD, et al. Expanding access to BRCA1/2 genetic counseling with telephone delivery: a cluster randomized trial. 7 Natl Cancer Inst 2014;106:dju328.

31. Physicians in Canada, 2018. Ottawa: Canadian Institute for Health Information; 2019.

32. Sanz J, Ramón y Cajal T, Torres A, et al. Uptake of predictive testing among relatives of BRCA1 and BRCA2 families: a multicenter study in northeastern Spain. Fam Cancer 2010;9:297-304.

33. Wang M, Aldubayan S, Connor AA, et al. Genetic testing for Lynch syndrome in the province of Ontario. Cancer 2016;122:1672-9.

34. Järvinen HJ, Renkonen-Sinisalo L, Aktán-Collán K, et al. Ten years after mutation testing for Lynch syndrome: cancer incidence and outcome in mutation-positive and mutation-negative family members. 7 Clin Oncol 2009;27:4793-7.

35. Public Bill (Senate) S-201 (42-1) (Royal Assent) Genetic Non-Discrimination Act Ottawa: Parliament of Canada; 2017 May 4.

36. Supreme Court of Canada. Case in brief: reference re Genetic Non-Discrimination Act. Available: https://www.scc-csc.ca/case-dossier/cb/2020/38478-eng.aspx (accessed 2020 Sep. 24)

37. Kerner J, Liu J, Wang K, et al. Canadian cancer screening disparities: a recent historical perspective. Curr Oncol 2015;22:156-63.

Affiliations: Department of Biology (Beard, Lee, J.E.J. Bedard), University of the Fraser Valley, Abbotsford, BC; Hereditary Cancer Program (A.C. Bedard, Nuk, Hong, Sun, Schrader), BC Cancer; Division of Medical Oncology (Sun), University of British Columbia; Department of Molecular Oncology (Schrader), BC Cancer; Department of Medical Genetics (Schrader), University of British Columbia, Vancouver, BC

Contributors: Vivienne Beard, Angela Bedard, Jennifer Nuk, James Bedard, Sophie Sun and Kasmintan Schrader conceived the study. Vivienne Beard, Angela Bedard, Petra Lee and Quan Hong curated and analyzed the data. Vivienne Beard and Angela Bedard wrote the original draft of the article, which all authors revised. All authors approved the final version to be published and agreed to be accountable for all aspects of the work. Vivienne Beard and Angela Bedard are joint first authors. Sophie Sun and Kasmintan Schrader are joint senior authors.

Funding: Kasmintan Schrader is supported by the Michael Smith Foundation for Health Research and the Canadian Institutes of Health Research.

Data sharing: The data that support the findings of this study are available in aggregate form on request from the corresponding author. The data are not publicly available because of privacy or ethical restrictions.

Acknowledgment: The authors thank the patients and families of the Hereditary Cancer Program of BC Cancer.

Supplemental information: For reviewer comments and the original submission of this manuscript, please see www.cmajopen.ca/content/8/4/ E637/suppl/DC1. 